\title{
Analyzing Demographics: Assessing Library Use Across the Institution
}

Shane Nackerud, Jan Fransen, Kate Peterson, Kristen Mastel

Note: This article will be published in the April 2013 issue of portal: Libraries and the Academy

\section{Abstract}

In Fall 2011, staff at the University of Minnesota Libraries-Twin Cities undertook a project to measure how often, and in what ways, students used the Libraries' services. Partnering with the University's Office of Institutional Research, the team investigated ways to match library service usage to individual accounts while retaining patron privacy to determine who was - and was not - using the library. With complete data sets, the group was able to determine overall usage rates for undergraduate and graduate students and compare how students in different colleges used library services. This article discusses data gathering techniques, analysis, and initial findings.

\section{Introduction}

Libraries play a key role in the academic success of students. Long gone are the days where libraries can simply report statistics; during these difficult budgetary times we need to demonstrate our value to administration and our community. Libraries have shifted from anecdotal evidence of library interactions and student success to data-driven investigations of libraries' impact on the research and learning mission of the institution.

During Fall 2011, staff at the University of Minnesota Libraries - Twin Cities began a study investigating how libraries can better measure student usage of library resources and 
services. We began the study with the intention of identifying as many measurable points of library access as possible and developing methods for recording users' interactions with the Libraries at those access points. We hoped to eventually correlate library use to student success measures such as GPA and retention, but in this initial pass we sought to answer the following questions:

- Do sufficient measures exist to determine what services individual library patrons use?

- Do the Libraries reach the majority of students in some way?

- Do students in different colleges use library materials and services in different ways?

- How does undergraduate library use compare to that of graduate students?

Usage statistics for the Fall 2011 semester (September 6 - December 22, 2011) with individual student identifiers intact, were gathered for thirteen different library services and resources, including circulation, digital resource usage, online reference transactions, workshop registrations, and more. The library project team then partnered with the U of M Office of Institutional Research to answer the research questions above. In this study we discuss the demographic data revealed through undergraduate and graduate student usage of library resources at a large academic research university.

\section{Literature Review}

Gathering data to measure use is nothing new to libraries. Although primarily focused on collections, staff, and expenditures, the Association of Research Libraries (ARL) included statistics on interlibrary loan lending and borrowing as early as $1974 .^{1}$ In the years since, ARL has added more use-focused measures, such as reference, instruction, and circulation. ${ }^{2}$ These 
measures, while useful for investigating changes over time and differences among institutions, do not reveal much about the library users themselves.

One way to find out how students and others are using libraries is to ask them. As in other aspects of academic life, students are often asked to complete library surveys. George D. Kuh and Robert M. Gonyea used survey responses gathered between 1984 and 2002 to reveal a trend toward less reported use of the library but more reported contact with librarians. ${ }^{3}$ Survey responses, however, are influenced by perception and questions are open to interpretation. For example, students still associate the library with books before all else, but circulation and in-house use are steadily dropping. ${ }^{4}$ As libraries provide more seamless access to online resources, students may not realize that it is the library providing the access.

Surveys have also been used to gauge students' information literacy and other library-influenced skills. However, Melissa Gross and Don Latham demonstrated that students whose performance on an information literacy skills test indicated low proficiency were likely to greatly overestimate their level of proficiency both before and after the test. ${ }^{5}$

In her ACRL report "Value of Academic Libraries," Megan Oakleaf urges librarians to collect the data needed to track the library interactions for individual users:

For instance, until libraries know that student \#5 with major A has downloaded B number of articles from database $\mathrm{C}$, checked out $\mathrm{D}$ number of books, participated in E workshops and online tutorials, and completed courses F, G, and H, libraries cannot correlate any of those student information behaviors with attainment of other outcomes. Until librarians do that, they will be blocked in many of their efforts to demonstrate value. ${ }^{6}$ 
Oakleaf acknowledges that libraries must continue to protect individuals' privacy. Karen A. Coombs notes that "the privacy tightrope stretches between the libraries' protection of user privacy and their fulfillment of institutional mission and goals." ${ }^{, 7}$ Coombs goes on to recommend specific actions to libraries that seek to improve services and collections by using data generated by user interaction.

In the last two years, several studies have brought together individual library use patterns and student demographic and success measures. Jennifer Link Jones describes Georgia State University Library's use of swipe-card data to determine demographic characteristics of library building users. $^{8}$ Gaby Haddow and Jayanthi Joseph were able to show a relationship between logins (to a library PC, database, catalog, or eReserves) and student retention. ${ }^{9}$ Sue White and Graham Stone described the initial process and findings of the JISC-funded Library Impact Data Project. ${ }^{10}$ Stone, Bryony Ramsden, and Dave Pattern provided an update, stating that "all indications show the project will have enough data to be able to prove that: statistically significant correlation across a number of universities between library activity data and student attainment."11 Shun Han Rebekah Wong and T.D. Webb showed a correlation between number of items checked out over the course of their academic career and students' GPAs at graduation. ${ }^{12}$ Brian L. Cox and Margie Jantti seek to bring together library data (loans and e-resource use) with student demographics and success factors in a data warehouse, or "library cube" that will be maintained on an ongoing basis for continuous process improvement. ${ }^{13}$

In our initial study, we measured student interactions in as many ways as were possible at the time we began. The data collected allow us to look broadly for patterns in use and 
relationships between different types of use and measures of student success, and also begin to balance ease of data collection with potential information gained.

\section{Methods}

\section{Library Data Collection}

In order to accomplish the project goals, we sought to gather usage data from as many different library services and resources as possible. This includes circulation loans and renewals, interlibrary loan requests, database, e-journal, e-book, and website usage, instruction activity such as workshop registrations, and reference transactions, especially online reference. Altogether, we recorded transactions in thirteen separate library resource and service usage areas (see Table 1). We wanted to develop as clear and as accurate a picture as possible of just how many University of Minnesota undergraduates and graduate students use library services.

At the University of Minnesota, all students are assigned an Internet ID that they use to $\log$ in to University resources such as e-mail and library resources through a central authentication mechanism. For the purposes of this study, Internet IDs were tied to library resource and service usage in order to eventually make demographic analysis possible. However, this was done with varying levels of success. For example, circulation logs for all loans and renewals include the patron's Internet ID. However, the group did not track questions asked at physical reference desks since Internet IDs are not typically requested or provided during these transactions. By tracking use at the Internet ID level, representative colleges, majors, and success measures could be determined from the data. 
Obviously this creates some issues with regard to privacy. Typically a library will track resource and service usage, but not retain any identifiable user information. For example, most libraries have extensive data on how many times licensed online databases or e-journals are used, but very few libraries keep track of exactly who is using those resources. At the University of Minnesota, project team members quickly realized that it would be essential to retain Internet IDs for the purposes of this project, but efforts were also made to retain as much user privacy as possible. Therefore, it was decided to track user data without tying the data to specific user transactions. That is, Internet IDs were captured and tied to broad activities, but not to the specific resource or service used. For example, when a user logged into a database, their Internet ID and the fact that they logged into a database were captured and retained, but the actual database used or queries executed were not. When a user registered for a workshop, again their Internet ID and the fact that they registered for a workshop were captured and retained, but the name of the workshop was not. The Internet IDs represented in the data were not de-duplicated, allowing us to take into account frequency of use for all data types. In this way, we gathered library resource and service transactions for the following thirteen access points throughout the Fall 2011 semester.

\section{Loans}

Loan data, both check-outs and renewals and including print reserves circulation, were extracted from the University of Minnesota Ex Libris Aleph catalog transaction records. Only the Internet ID and the date of the transaction were retained. Again, data used for this study did not contain any actual titles of items checked out. Altogether, 252,614 loan transactions were recorded 
(138,171 loans and 114,443 renewals). Loan data was the most complete set of transactions recorded, since all records contained an Internet ID and all data was captured by a single system.

\section{Interlibrary Loan Requests}

Interlibrary loan (ILL) data was captured through ILLiad, an ILL management system provided and hosted by OCLC. At the time of this project, Fall 2011, ILLiad users created their own ILLiad account. As part of the account creation, users were instructed to use their Internet ID, and the vast majority of users did that. However, a small number of users created unique ILLiad user IDs and therefore their transactions were not recorded for this study. Since then the University has successfully tied ILLiad authentication to an institutional central authentication system. During the Fall 2011 semester, 17,041 ILL transactions with usable Internet IDs were recorded.

\section{Digital Resource Usage}

Transactions for licensed database, e-journal, e-book, and website logins were all recorded in the same way. The Libraries make use of a "click-thru" script for licensed resources that authenticates and authorizes users and launches them into the University of Minnesota installation of EZProxy. This click-thru script is included on all licensed resource transactions through the Libraries website, or if a patron has bookmarked a library-created click-thru link. With this infrastructure already in place, team members included a script to record, in a separate MySQL database, the Internet ID and broad transaction type when a person logged into any of the digital resources above. Due to IP-based authentication, this method does not record all on-campus usage of databases, e-journals, and e-books. However, Internet ID can often be 
captured anyway, if the on-campus user has logged into another service, such as campus e-mail. Using this recording methodology, licensed database, e-journal, e-book, and website logins accounted for $1,110,727$ transactions, or approximately 72 percent of all transactions recorded in the project.

\section{Workstation Usage}

For access to the majority of computer workstations within the Libraries, users are required to $\log$ in with an Internet ID and password through a shared computer management service called CybraryN. However, during the Fall 2011 semester, computers within the Libraries SMART Learning Commons did not yet utilize CybraryN and were not included in this study. Interestingly, besides using the library to check out items, this is the only measure that recorded usage of a library service actually within library buildings (or "library as place"). In-library workstation usage totaled 159,316 logins for the Fall 2011 semester.

\section{Course-integrated instruction}

Liaison librarians frequently coordinate with faculty members to deliver in-class library instruction. Librarians enter the course, section, date, and other information into the DeskTracker database used for reference transactions. In order to gather Internet IDs for analysis, the group used class lists available through UM Reports, a centralized data repository maintained by the University's Office of Information Technology. For each class logged in DeskTracker, staff ran the appropriate class list report and added students' Internet IDs to a spreadsheet. However, there 
is no way to know whether an individual student actually attended the librarian's instruction session.

\section{Introduction to Library Research}

Introduction to Library Research Part 1 and Introduction to Library Research Part 2 are workshops offered by the Libraries. These workshops, typically taken in conjunction with the freshman writing course, are available to anyone online. Part 1 is also offered as an in-person workshop. Internet IDs are collected when students complete and turn in a worksheet to receive credit for attending the workshop from their instructors.

\section{Peer Research Consulting}

Undergraduates can receive one-on-one assistance from the Libraries' team of Peer Research Consultants. The Peer Research Consultant service offers trained undergraduates who help students narrow down their topic, choose keywords, evaluate articles and websites, and perform other key research skills. Consultations are by appointment, so Internet IDs were harvested from appointment lists for this study.

\section{Online Reference Usage}

Although reference services remain an important means of interaction between students and library staff, gathering data on who asks reference questions is particularly difficult. Reference desk staff and liaisons focus on the patron's question rather than their identity, and identifying information is almost never recorded. 
There is one aspect of reference service that typically does include an Internet ID: online transactions captured through OCLC QuestionPoint. Students asking questions through chat or e-mail with the Libraries' "Ask Us" service are required to enter an e-mail address. This address is almost always the same as their Internet ID. For this study, the group downloaded the QuestionPoint data for Fall 2011 and parsed that into a list of Internet IDs.

\section{Workshop Registrations}

The Libraries hosts in-person workshops throughout the year in four on-campus libraries. Students, faculty, and staff can register for these free workshops through the Libraries' Drupal registration module. Registration information, including Internet ID, is readily available in Drupal. However, because these are free workshops, students often walk in without registering, or choose not to attend without canceling their registration. The Libraries have no mechanism in place for updating workshop lists to reflect attendance rather than registration.

\section{Overall Counts}

Even before working with the Office of Institutional Research (OIR), the project team was able to learn a great deal about library resource and service usage through the raw numbers collected for each library access point. Transaction statistics for each of the thirteen areas are summarized in Table 1. 


\begin{tabular}{|l|r|r|}
\hline Access Point & Number of Unique Internet IDs & Number of Transactions \\
\hline Loans and renewals & 21,993 & 252,614 \\
\hline Interlibrary Loan requests & 3,677 & 44,041 \\
\hline Database logins & 38,328 & 522,299 \\
\hline E-Journal logins & 30,105 & 65,204 \\
\hline E-Book logins & 10,455 & 79,052 \\
\hline Website logins & 17,436 & 104 \\
\hline Peer Research Consulting appts. & 9,39 \\
\hline Online reference transactions & 2,398 & 3,143 \\
\hline Workshop registrations & 378 & 494 \\
\hline Intro to Library Research Part 1 & 1,341 & 1,341 \\
\hline Intro to Library Research Part 2 & 458 & 483 \\
\hline $\begin{array}{l}\text { Course-integrated instruction } \\
\text { opportunities }\end{array}$ & 2,563 & 2,964 \\
\hline Workstation logins & & 159,316 \\
\hline \hline Total & 16,900 & $\mathbf{1 , 5 4 8 , 2 0 9}$ \\
\hline
\end{tabular}

Table 1. Count of unique Internet IDs and total transactions by access point.

Numbers in the second column represent unique Internet IDs, while numbers in the third column represent total transactions. That is, 21,993 individuals checked out or renewed a total of 252,614 items during Fall 2011.

To simplify initial processing, the thirteen access points were combined into five broad types of access:

- Circulation: Loans and interlibrary loan requests

- Digital: Database, e-journal, e-book, and website logins

- Reference: Peer research consultations and online reference transactions

- Instruction: Workshop registrations, Introduction to Libraries participants, and course-integrated instruction

- Workstation 
Transaction statistics for the five access types are summarized in Table 2.

\begin{tabular}{|l|c|c|}
\hline Access Point & Number of Unique Internet IDs & Number of Transactions \\
\hline Circulation & 23,425 & 269,655 \\
\hline Digital & 47,197 & $1,110,727$ \\
\hline Reference & 2,479 & 3,247 \\
\hline Instruction & 4,088 & 5,264 \\
\hline Workstation & 16,900 & 159,316 \\
\hline
\end{tabular}

Table 2. Transaction data summarized into five access types.

Further investigation revealed that the average number of transactions per user was 25.29. However, this was skewed somewhat by outliers, such as one individual who checked out or renewed (mostly renewed) 9,324 items. Only three people interacted with the library in ten of the library access points measured during the Fall 2011 semester. No one interacted with all thirteen access points, and 23,807 people interacted with only one access point. Some people may have interacted with one access point hundreds of times, such as e-journal usage, but again only in that one access point. People interacting with two or more access points numbered 37,388.

Altogether, the project team compiled 1,548,209 individual transactions and 61,195 individual Internet IDs tied to those transactions.

\section{Demographic Data and Analysis}

A single Excel spreadsheet of Internet IDs tied to the five broad types of access was sent to the Office of Institutional Research so they could add demographics and other data to individual records. The final data set contained all students, library users and non-library users alike, and included the following demographic information: 
- Level (graduate, undergraduate, professional, non-degree seeking)

- College of enrollment

- Major

- Gender

- Ethnicity

- Student of Color flag

- Part-time flag

- Age range

- Term GPA and Cumulative GPA

- A yes or no flag for each of the five summarized data access points listed in Table 2.

At this point, Internet IDs were removed from the data, creating an anonymized set. With all students included, whether they used the library or not, we could explore trends indicating library utilization by college, gender, student level, and more.

\section{Results}

Initial data analysis provided by the Office of Institutional Research revealed that during the Fall 2011 semester 77 percent of all undergraduate students and 85 percent of all graduate students made use of the University Libraries in a measurable way.

Demographic data also provided some interesting information regarding who uses the Libraries, as shown in Figure 1. For example, the group found that 100 percent of Pharmacy professional students made use of the Libraries during the Fall 2011 semester. No other school or 
department had 100 percent of students using the Libraries. Veterinary Medicine professional students had the lowest percentage of users at sixty percent of students.

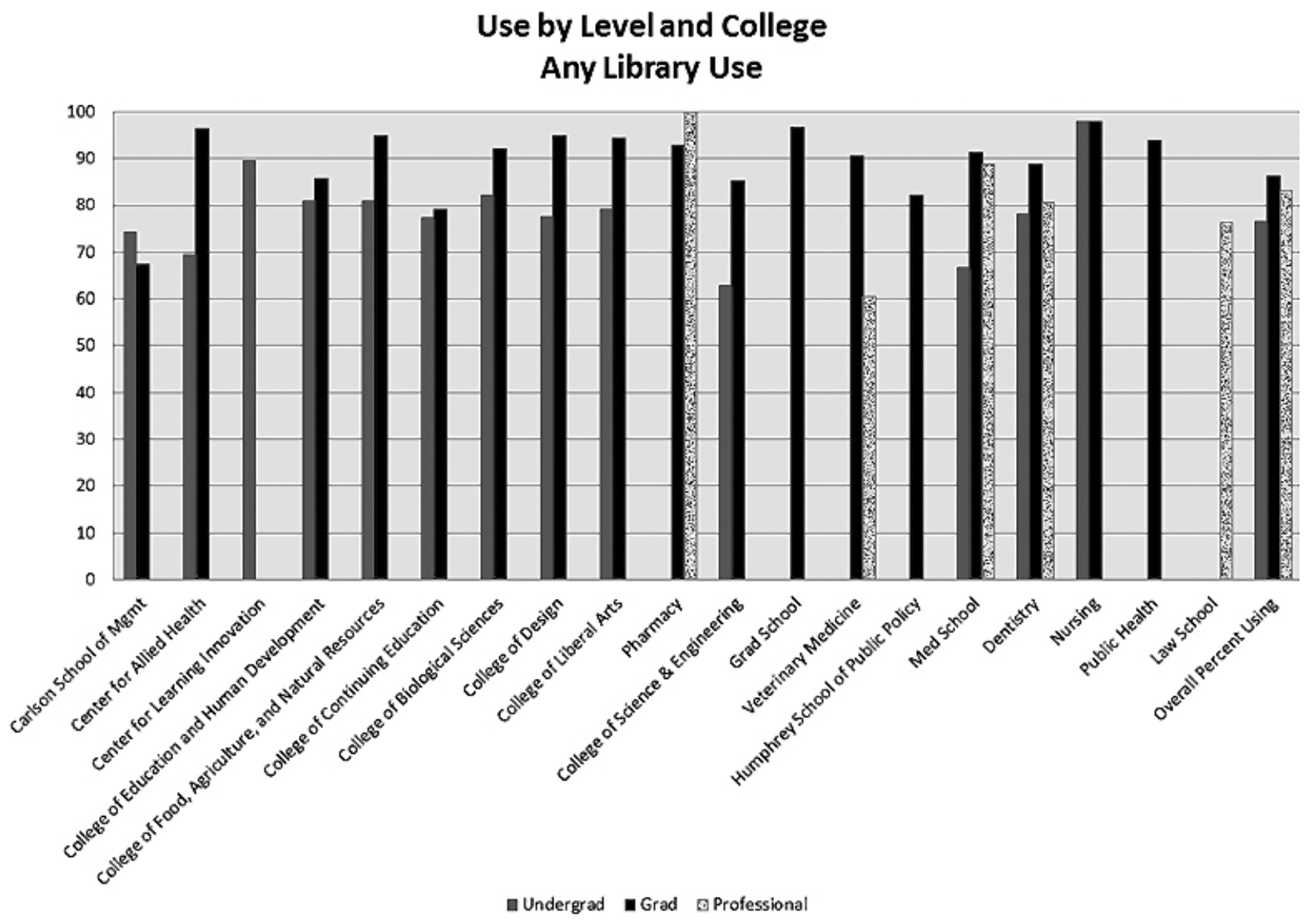

Figure 1. Percent of students at each level making use of the Libraries, by college of enrollment.

Graduate students tended to use library services measured in this study more than undergraduates. The Carlson School of Management (CSOM) was an exception: 74 percent of CSOM undergraduates used the libraries as opposed to 67 percent of graduate students. 
College- and level-specific patterns also emerged as we analyzed each of the five summarized access points separately. As expected, digital resource usage represented the highest level of interaction between students and the library. Taking only digital resource usage into account, 65 percent of undergraduates made use of licensed online indexes, e-journals, e-books, or logged into the library's website. Eighty-two percent of graduate students made use of digital resources through the library. Seventy-four percent of College of Education and Human Development undergraduate students used digital resources such as databases or e-journals to lead in that category, while only 47 percent of College of Science and Engineering students did the same.

Regarding other categories of usage, 23 percent of undergraduates and 42 percent of graduate students took advantage of circulation services offered through the Libraries, with the College of Design undergraduates and graduate students making more use of circulation services than their counterparts in other colleges. Ninety percent of graduate students in the College of Design checked out or renewed an item, or made an interlibrary loan request. Thirty-seven percent of College of Design undergraduates checked out or renewed at least one item. On the other end of the spectrum, only thirteen percent of undergraduates and ten percent of graduate students in the Carlson School of Management made use of circulation services.

Other categories of library use included workstation usage where only 25 percent of graduate students logged into a library workstation during the Fall Semester, with undergraduate usage somewhat higher at 34 percent. Reference and instruction activities represented the lowest level of usage for undergraduate students and graduate students. Graduate student and 
undergraduate usage in both areas was below ten percent. However, in the Medical School specifically, thirty percent of graduate students took advantage of library instruction services.

In addition to analysis regarding library access point usage for colleges and departments represented in the data, the Office of Institutional Research was also able to provide data regarding academic success of library users. During the Fall 2011 semester, undergraduate students who made at least one use of the library in any of the library access points consistently had higher semester GPAs than students who made no use of the library. For example, students in the College of Food, Agriculture, and Natural Resource Sciences that made use of the Libraries had an average GPA of 3.14 while students in that college that made no use of the library had an average GPA of 2.92 . 


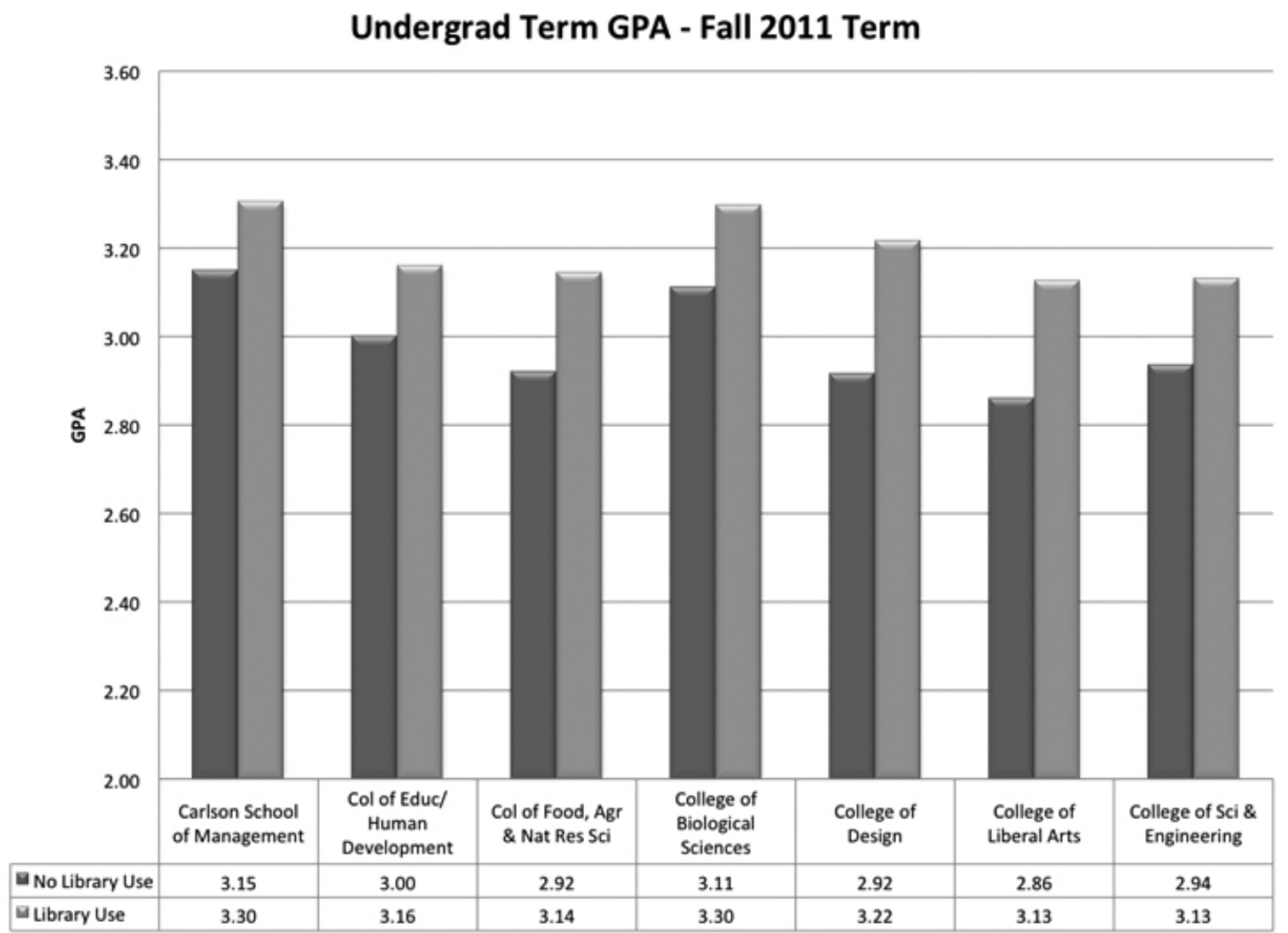

Figure 2. Term GPA by college: Non-library users vs. library users.

\section{Discussion}

In this study, we sought to answer a number of research questions regarding undergraduate and graduate student library usage at the University of Minnesota. Who are these students? What colleges do they represent? Does the library reach a majority of students in some measurable way? Answering these questions required that we retained personally identifiable usage information in our data gathering practices. In fact, the success of this project was determined in large part by a relaxing of the privacy restrictions around usage tracking that have guided libraries since the advent of the World Wide Web. Retaining a connection between actual 
Internet IDs and the broad library service or resource accessed is essential for this type of study. Without those Internet IDs, we would not have been able to conduct the rich demographic analysis or uncover the helpful statistics that resulted from this study.

The project team was encouraged by the demographic analysis and statistics revealed in partnership with the Office of Institutional Research. Even with the limitations in the data collection process, basic results showed that 77 percent of undergraduate students and 85 percent of graduate students made use of the library during the Fall 2011 semester. If data collection processes are improved and methods are developed to measure other access points, those numbers are likely to be even higher. Specifically, we are seeking ways to better measure use of the library as place, and impact of "high touch" services such as in-person reference interactions.

Library workstation use is the only measurement in this study that tracks usage of library as place. Other measures are being considered to better gauge library building use, such as reference desk transactions and one-on-one consultations, but unless Internet IDs are gathered for all interactions, including entering the building, further understanding of usage of "library as place" may not be possible in regard to this study.

While the analysis of student usage of access points like reference and instruction services revealed lower levels of use, it seems likely that students who have one-on-one interactions with librarians are benefiting from those interactions. In fact, in a separate study at the University of Minnesota using this same data, one specific aspect of library instruction was shown to have a very strong association with retention for undergraduates that took the instruction course. However, as with swiping cards to enter a library building, collecting Internet IDs for every personal interaction introduces a barrier. As this project moves to the next stage, 
we must consider whether identifying data can be collected without compromising privacy or discouraging students from seeking out the interaction.

When looking at columns of numbers for the different access points, one naturally begins to use them to compare those access points to each other. However, the nature of each is unique. We hope that all students make use of electronic resources during each semester of enrollment. But we would not want students to feel a need to take the Intro to Library Research workshops more than once or twice in their college careers. The latter should be preparing students for effective ongoing use of the former.

With the relationships among the access points in mind, further study is needed to analyze the impact of one access point on another. For example, does workshop attendance result in higher use of licensed indexes or e-journals in subsequent semesters? The project team has only scratched the surface concerning this type of question. Can we successfully measure whether the foundation we lay out through reference interactions and instruction sessions is truly effective, both in the short term and throughout a student's academic career? Early analysis does suggest that we can see and build connections between these data points in order to demonstrate their impact and relationship to each other.

Analysis of the GPAs for library users vs. non-library users also demonstrates the need for further studies that attempt to correlate library usage with student success measures such as retention and grades received. So far, studies in this area using this same data and controlling for other factors related to student success have demonstrated that first year undergraduate students who use the library have a higher GPA for their first semester and higher retention from fall to spring than non-library users. The results of this facet of the study are published here as a 
separate article titled "Library Use and Undergraduate Student Outcomes: New Evidence for Students' Retention and Academic Success."14

Of course, correlation does not mean causation. However, revealing associations within the data is an important part of establishing the library's value to the University. Already library staff have been able to share this data with University deans and administration and the feedback has been both positive and somewhat unexpected. For example, while University administrators have been enthused by the results, they are also not surprised. It seems intuitive that libraries should be able to demonstrate appropriate levels of usage, and that usage should result in increased academic success. But from a library standpoint, it is helpful to justify investment in libraries with actual numbers, correlative or not, rather than just anecdotal evidence. We look forward to other libraries and universities conducting this kind of work so we can compare and contrast results.

Throughout this project, our partnership with the Office of Institutional Research (OIR) has been extremely valuable. While project team members have a rudimentary understanding of statistical analysis and techniques, OIR has made it possible to quickly and authoritatively determine the significance of the data we have gathered. There may be a misconception within the library profession that this kind of knowledge must be present in-house for this kind of study to be successful. We encourage other academic libraries to seek out their own departments of institutional research and analysis. Their advice, access to student and demographic data, and expertise in analytical methods can help make this type of work go more smoothly. Our partnership with OIR has been mutually beneficial as we have gained a better understanding of 
how students make use of our services and resources, and OIR has demonstrated once again to the rest of campus how valuable their services can be.

To date, this phase of the study has led to much discussion but has had little impact on decision making. Going forward, data from Fall 2011 and subsequent semesters could be used to help answer questions like these:

- Can these data inform collection development strategies, particularly in how strategies differ from one college or level to another?

- Could these data help the libraries target marketing efforts toward particular colleges and departments, or groups of users?

- Certainly this study has already suggested new ways to gather data and usage statistics, but are there other ways this data could help inform improvements in library processes? The project team anticipates that the work of this study should and will affect library planning and decision making. As Ross Housewright describes, evidence can help explain not only one's foundational importance, but also "identify existing services no longer of good value, adoption of new services, and assist with communicating the value of the library." 15 With that in mind, we plan to continue this study in subsequent semesters, and possibly even get a four year snapshot of library use for a cohort of students throughout their academic career. We are also looking at ways to more easily collect or automate the collection of the usage data from the thirteen current library access points, and adding access points, especially in regard to special collection use.

\section{Conclusion}


The power of this study is that it shows how libraries can pull together a relatively complete picture of library use by standardizing the capture of usage statistics in a number of typical library services, and tying that usage to personally identifiable information. It is essential that usage statistics gathered include personally identifiable information while also maintaining an acceptable degree of user privacy. Resulting analysis can show who our users are, and how they use our libraries. We found that the majority of students, both graduate and undergraduate, used the Libraries' resources and services over the Fall 2011 semester. In fact, if usage statistic gathering techniques can be improved, the percentages of undergraduate and graduate usage are likely to be even higher. Reaffirming prior anecdotal evidence we saw clear trends of different disciplines using different services, such as College of Design students' heavy use of the physical collection, and College of Education and Human Development students' use of electronic resources. Further analysis is needed to determine the impact these interactions will have over a student's college career, along with how various data points interact with each other. In the case of the University of Minnesota, this study revealed encouraging undergraduate and graduate student library usage levels and a compelling demographic snapshot of how students use the library. Combined with correlative studies tying library usage data to student success measures, this demographic analysis of who our users are and how they use the library has become a powerful demonstration of the library's value to the institution.

At the University of Minnesota - Twin Cities, Walter Library, Minneapolis, Shane Nackerud is Technology Lead, eLearning Support Initiative, e-mail snackeru@umn.edu; Jan Fransen is Engineering Librarian, e-mail fransen@umn.edu; Kate Peterson is Information Literacy 
Librarian; katep@umn.edu. At the University of Minnesota -Twin Cities, Magrath Library, St. Paul, Kristen Mastel is Outreach and Instruction Librarian,e-mailmeye0539@umn.edu.

\section{Notes}

${ }^{1}$ Kendon Stubbs and Robert E. Molyneux, Research Library Statistics 1907-08 through

2 Association of Research Libraries, “ARL Statistics and Assessment Timeline,” 2010 http://www.arl.org/stats/statsresources/timeline print.shtml (accessed 4 January 2013).

${ }^{3}$ George D. Kuh and Robert M. Gonyea, "The Role of the Academic Library in Promoting Student Engagement in Learning," College \& Research Libraries 64, 4 (2003): 256-282.

${ }^{4}$ OCLC Online Computer Library Center Inc., College Students' Perceptions of Libraries and Information Resources (Dublin, OH: OCLC Online Computer Library Center, Inc., 2006), http://www.oclc.org/reports/pdfs/studentperceptions.pdf; Bill V. Opperman and Martin Jamison, "New Roles for an Academic Library: Current Measurements," New Library World 109, 11/12 (2008): 559-573; Charles Martell, “The Absent User: Physical Use of Academic Library Collections and Services Continues to Decline 1995-2006," Journal of Academic Librarianship 34, 5 (2008): 400-407.

${ }^{5}$ Melissa Gross and Don Latham, "Undergraduate Perceptions of Information Literacy: Defining, Attaining, and Self-Assessing Skills," College \& Research Libraries 70, 4 (2009): 336-350. 
${ }^{6}$ Megan Oakleaf, The Value of Academic Libraries: A Comprehensive Research Review and Report (Chicago: Association of College and Research Libraries, 2010).

7 Karen A. Coombs, "Walking a Tightrope: Academic Libraries and Privacy," Journal of Academic Librarianship 30, 6 (2004): 493-498.

8 Jennifer Link Jones, “Using Library Swipe-card Data to Inform Decision Making," Georgia Library Quarterly 48, 2 (2011): 11-13.

9 Gaby Haddow and Jayanthi Joseph, "Loans, Logins, and Lasting the Course: Academic Library Use and Student Retention," Australian Academic \& Research Libraries 41, 4 (2010): $233-244$.

10 Sue White and Graham Stone, "Maximizing Use of Library Resources at the University of Huddersfield," Serials: The Journal for the Serials Community 23, 2 (2010): 83-90.

${ }^{11}$ Graham Stone, Bryony Ramsden, and Dave Pattern, "Looking for the Link Between Library Usage and Student Attainment," Ariadne (Online) 30, 67 (2011): 46-51.

12 Shun Han Rebekah Wong and T. D. Webb, "Uncovering Meaningful Correlation Between Student Academic Performance and Library Material Usage," College \& Research Libraries 72,4 (2011): 361-370.

13 Brian L. Cox and Margie Jantti, "Capturing Business Intelligence Required for Targeted Marketing, Demonstrating Value, and Driving Process Improvement," Library \& Information Science Research 34, 4 (2012), 308-316.

14 Krista Soria, Jan Fransen, and Shane Nackerud, "Library Use and Undergraduate Student Outcomes: New Evidence for Students' Retention and Academic Success," portal: Libraries and the Academy 13, 2 (2013): [page numbers forthcoming]. 
15 Ross Housewright, "Themes of Change in Corporate Libraries: Considerations for Academic Libraries," portal: Libraries and the Academy 9, 2 (2009): 253-271. 